Reprod. Nutr. Dévelop., 1982, 22 (1 A), 1-25.

\title{
A stereotaxic atlas and technique for nuclei of the diencephalon of rainbow trout (Salmo gairdneri)
}

\author{
R. BILLARD, R.E. PETER (*)
}

with the technical assistance of J. L. BARBREL, Anne-Marie ESCAFFRE and Chantal CAUTY

Laboratoire de Physiologie des Poissons, I.N.R.A. 78350 Jouy-en-Josas, France.

(*) Department of Zoology, University of Alberta, Edmonton, Alberta T6G 2E9, Canada.

Summary. A stereotaxic apparatus and technique for electrode placement in diencephalic nuclei of sexually immature rainbow trout of $120-140 \mathrm{~g}$ body weight is described. An atlas of nuclei in the diencephalon is also presented.

\section{Introduction.}

A stereotaxic atlas and technique for forebrain nuclei of the goldfish Carassius auratus (Peter, 1970 ; Peter and Gill, 1975) and the killifish, Fundulus heteroclitus (Peter et al., 1975) have previously been described. For these stereotaxic techniques specially designed head holders were developed to maintain the head of the fish rigid in a certain position, and zeroing was by a point on the exposed surface of the brain. These techniques have been successfully used in studies on neuroendocrinology and behaviour in goldfish (e.g. Peter, 1970, 1977 ; Billard and Peter, 1977 ; Peter and Paulencu, 1980) and killifish (Macey et al., 1974). In other studies a modified mammalian stereotaxic apparatus has been used for implantation of electrodes in the exposed brain of several teleost species for stimulation or recording in behavioural studies (e.g., Demski, 1978). The present study describes a stereotaxic atlas and technique for the diencephalon of rainbow trout (Salmo gairdneri) of $120-140 \mathrm{~g}$ body weight in which the classical approach of skull coordinates was used. During its development, this technique was used in neuroendocrine studies (Crim et al., 1981) and it has been an essential tool for additional studies in progress (R. Billard, L. Crim, H. Goos and R. Peter, unpublished results). 


\section{Materials and methods.}

The stereotaxic apparatus is illustrated in figures $1 \mathrm{a}, \mathrm{b}$. This stereotaxic technique is applicable to sexually immature rainbow trout of $130 \pm 10 \mathrm{~g}$. The head holder is a 3-point system of attachment, consisting of 2 orbital bars, one inserted on the upper rim of each orbital bone ring (fig. 1b), and a mouth bar against the roof of the mouth. The apparatus consists of a metal base plate supporting a vertical tube on which are fixed two horizontal bars (left horizontal bar shown in fig. 1a, both are shown in fig. 1b) that serve to support the head holder and electrode holder. Both horizontal bars are square and are mounted in such a manner that an edge is towards the base plate. The horizontal bars are marked with a $\mathrm{mm}$ scale. An orbital bar is fixed to the underside of each

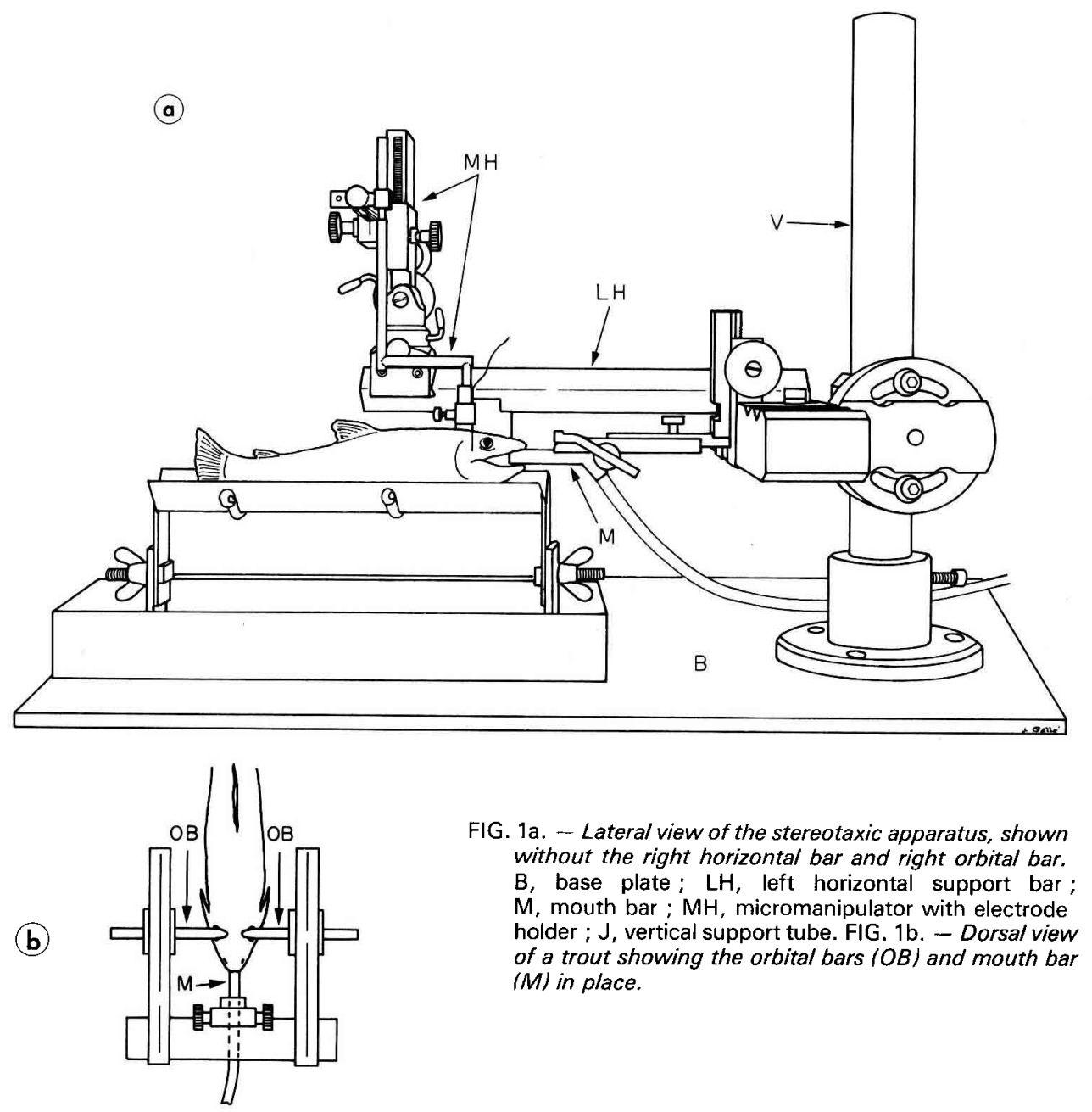


horizontal bar equidistant from the main vertical support tube. The distal ends of the orbital bars are rectangular and can slide laterally in the clamps attached to the horizontal bars, allowing them to be clamped in any lateral position. The orbital bars and their respective clamps are marked with $\mathrm{mm}$ scales to allow clamping the bars in similar positions. The proximal end of each orbital bar is grooved according to the dimensions given in figure 2a. The upper surface of each orbital bar has a shallow groove (fig. 2b) that is used for zeroing (see below). The mouth bar is attached medially between the two horizontal bars to the same structure that supports the horizontal bars, and it can be moved vertically. For this technique the top of the mouth bar is set $7 \mathrm{~mm}$ below the top of the orbital bars and the tip of the mouth bar is $2.5 \mathrm{~mm}$ from the center of the orbital bars (fig. 2a, b) for each fish. The mouth bar is a hollow tube $10 \mathrm{~mm}$ in diameter (fig. 2a) and also serves as the inlet to the mouth for perfusion of the gills with anesthetic water. The electrode holder, in this apparatus a Narishige micromanipulator, is attached to a vertical rod that is itself attached to the left horizontal bar (fig. 1a). The three planes of operation of the electrode holder are squared to the horizontal and vertical planes of the head holder. The horizontal bar and the clamp attaching the electrode holder to it are marked with $\mathrm{mm}$ scales so that the electrode holder can be moved measured distances along the horizontal bar.

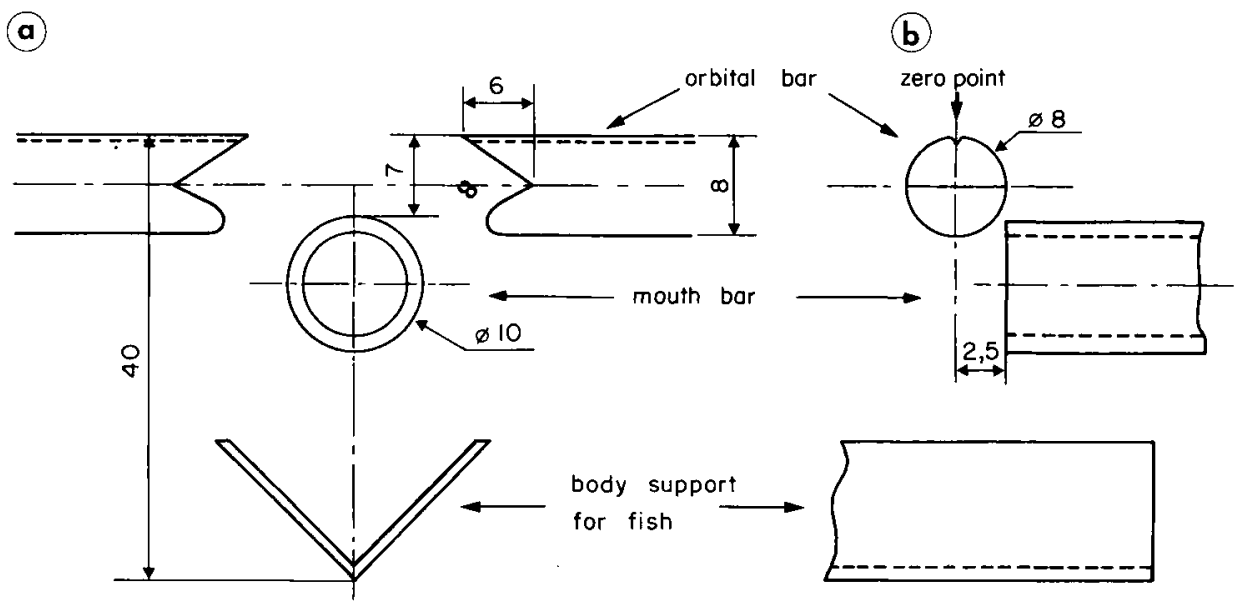

FIG. 2a. - Lateral view, to scale in $\mathrm{mm}$, of the orbital bars and end views of the mouth bar and body support for the fish. $2 \mathrm{~b}$. - End view, to scale in $\mathrm{mm}$, of an orbital bar and lateral view of the mouth bar and body support for the fish.

The fish, anesthetized in water containing $0.3-0.5 \mathrm{ml}$ 2-phenoxyethanol $/ \mathrm{l}$, is supported by a V-shaped trough that sits inside a basin to collect the anesthetic water (fig. 1a). The mouth of the fish is centered over the mouth bar, and the orbital bars moved into position and clamped; the top of the skull should be approximately horizontal. The fish is perfused during the remainder of the 
procedure with anesthetic water $(0.3 \mathrm{ml}$ 2-phenoxyethanol/I), which is recirculated and continuously aerated.

The horizontal and anterior-posterior zero (fig. 3) of the stereotaxic procedure is the shallow groove on the upper surface of the orbital bars (fig. $2 b$ ). The midline zero is the midpoint between the proximal ends of the orbital bars. After zeroing and noting the position of zero on the scales of the micromanipulator and the horizontal bar, the electrode is raised and moved posteriorly a measured distance, according to the atlas coordinates. For the final placement of the electrode, a hole big enough for it to pass is drilled in the skull, the electrode lowered to the horizontal zero position, and then down the appropriate vertical distance for placement in the desired position. After the electrode is withdrawn, the hole is filled with surgical wax and closed with a drop of cyanoacrylic glue. The fish is then removed from the apparatus and returned to anesthetic-free water for recovery.

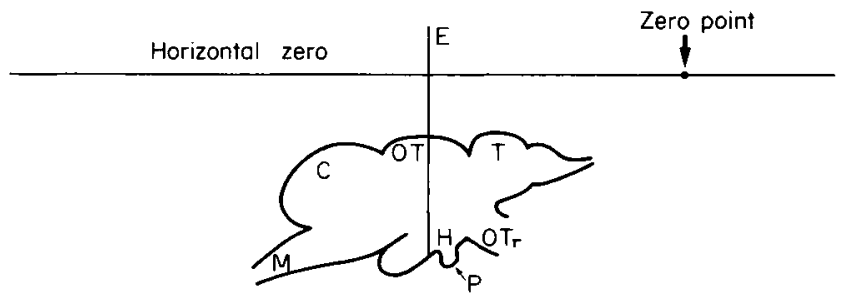

FIG. 3. - Outline drawing of a sagittal section of the trout brain showing the location of the zero point and the angle of intervention of an electrode $(E)$ into the brain. $\mathrm{C}:$ cerebellum, $\mathrm{H}:$ hypothalamus, $\mathrm{M}$ : medulla, OT : optic tectum, OT, : Optic tract, T : telencephalon.

\section{Preparation of the atlas.}

Ten sexually immature one year old rainbow trout, weighing $130 \mathrm{~g}$ after 3 days of starvation, were used. The fish were raised in earthen raceways and fed pelleted food twice daily. Each fish was placed on the stereotaxic apparatus, the top of the skull cut with a circular saw blade, and the brain exposed. In four of the fish, the brain was cross-sectioned at the level of the cerebellum using a razor blade attached to the electrode holder, and the anterior portion of the brain removed, with the pituitary attached, and fixed in Bouin's solution for 3 days. At embedding, the cerebellum section of the brain was placed against the bottom of the paraffin cup, and the angle of the cerebellum cross-section used as the guide for the angle for cutting sections in the same vertical plane as the electrodes in the stereotaxic apparatus (fig. 3). The other approach used was to leave electrodes in place in the brain during fixation, and use the electrodes as a guide for the plane of sectioning. After embedding, the top of two of these brains were cut off (horizontally cut) at a right angle to the plane of the electrodes, and then frontal sections were cut in the plane of the electrodes to enable correct vertical positioning of the sections relative to each other. Sections were cut at $8 \mu \mathrm{m}$ and stained with Epple's technique (1967). Pictures were taken of sections at intervals every $0.5,0.1$ or $0.2 \mathrm{~mm}$, and drawings made of selected sections. Tissue 
shrinkage of 3 p. 100, calculated by measurement in the sections of distances between electrode paths, was taken into account when tracing the grids with lines $0.5 \mathrm{~mm}$ apart on the left-hand side of the drawings. Posterior of the pituitary, the brain lies flat against the floor of the cranium; in addition to using the horizontally cut brains to get the vertical positioning of the grids relative to each other and the horizontal zero, measurements were made in several fish to confirm the depth from horizontal zero to the bottom of the brain where the electrode hit bone.

The atlas is given in Plates 1-38. The distance posterior from the anteriorposterior zero is given in $\mathrm{mm}$ at the top of each drawing. The distance between the atlas drawings is either $0.1,0.15,0.2,0.25$ and $0.4 \mathrm{~mm}$ so that major conformation changes are illustrated, without undue repetition of regions that are not changing greatly. The numbers on the grid on each drawing show the depth from the midline in $\mathrm{mm}$. The nomenclature for diencephalic nuclei, given in table 1, is the same as used for the goldfish (Peter and Gill, 1975).

TABLE 1

Nomenclature and list of abbreviations.

$\mathrm{AC}$, anterior commissure

$A P$, area pretectalis

$\mathrm{CM}$, Corpus mamillare

$\mathrm{NAH}$, nucleus anterioris hypothalami

NAPV, nucleus anterioris periventricularis

NAT, nucleus anterior tuberis

NC, nucleus corticalis

$\mathrm{NCH}$, nucleus cerebellosus hypothalami

NDL, nucleus dorsolateralis thalami

NDLI, nucleus diffusus lobi inferioris

NDM, nucleus dorsomedialis thalami

NDTL, nucleus diffusus tori lateralis

$\mathrm{NE}$, nucleus entopeduncularis

NG, nucleus glomerulosus

$\mathrm{NH}$, nucleus habenularis

NLG, nucleus lateral geniculatus

NLT, nucleus lateral tuberis

NP, nucleus pretectalis
NPGI, nucleus preglomerulosus pars lateralis

NPGm, nucleus preglomerulosus pars medialis

NPO, nucleus preopticus

NPP, nucleus preopticus periventricularis

NPPV, nucleus posterioris periventricularis

NPT, nucleus posterior tuberis

NR, nucleus rotundus

$\mathrm{NRL}$, nucleus recessus lateralis

NRP, nucleus recessus posterioris

NSV, nucleus saccus vasculosus

NTP, nucleus posterioris thalami

NVL, nucleus ventralis lateralis

NVM, nucleus ventromedialis thalami

OC, optic chiasma

Pit, pituitary

PC, posterior commissure

$\mathrm{SCO}$, subcommissural organ

$\mathrm{SV}$, saccus vasculosus

Tel, telencephalon

\section{Discussion.}

Although the procedure uses points of attachment to hold the head that are similar to other fish stereotaxic techniques, this procedure differs in that skull references were used for the zero point instead of a point on the dorsal surface of the exposed brain. The advantage of the present technique is that there is probably less chance of trauma to the brain. However, the skull coordinates are less precise ; there was about 70 p. 100 of success of placements of a hormone pellet in the NLT in the pituitary stalk region of rainbow trout (Crim et al., 1981 ; Billard and Peter, unpublished results) compared to 84 and 80 p. 100 for comparable placements in Fundulus and goldfish, respectively (Peter and Gill, 
1975 ; Peter et al., 1975). The difficulty in the present technique is to place accurately in the mid-line of the brain; the trout encephale can be slightly asymmetrical (Ridet et al., 1974), which creates this problem. Finding the mid-line accurately can be improved by drilling a hole about $1 \mathrm{~cm}$ diameter with a circular saw to enable visualization, but this exposure of the brain causes additional trauma and is also more difficult.

Because this technique is based on use of a population of rainbow trout available to us, and another population may have a somewhat different skull size and shape due to strain or rearing conditions, using a new population of fish may require some adjustment in the coordinates of the atlas, particularly the distances posterior of zero. This can be done by determining if some structure, such as the pituitary or posterior commissure, can be reached precisely by the atlas coordinates. Another means of testing the accuracy of placement is to fix the entire head of a fish, cut it longitudinally in half, and then place half of the head in the apparatus to directly visualize the accuracy of placements. Also, for fish of a body size outside the range of application of this technique, the latter procedure can be used to make same adjustment of coordinates. However, rainbow trout of a very different size (less than $100 \mathrm{~g}$, greater than $160 \mathrm{~g}$ ) require another atlas because the size of the brain is not in proportion to size of the head (Bauchot et al., 1973).

The nomenclature used for the diencephalic nuclei is the same as for goldfish (Peter and Gill, 1975). Some additional subdivisions of nuclei in the trout brain have been made by Ridet et al. (1974) and Ekengren and Terlou (1978), particularly in the NLT and NPO. Dubois et al. (1978, 1979) found that perikarya containing immunoreactive somatostatin were present in the NLT and NPP, but not in the NPO ; this confirms the distinction between the NPP and NPO, as suggested by Peter and Gill (1975). The trout NPO, as in other teleosts, is subdivided into the pars parvocellularis, containing small perikarya, and the pars magnocellularis, containing large perikarya ; Gomori-positive material appears earlier in the large NPO cells during ontogenesis (Plytycz, 1974), suggesting some functional differences between these two subdivisions of the NPO. Undoubtedly functional subdivisions in many nuclei will become evident with further studies. We hope that this stereotaxic atlas and technique will contribute to such studies.

Reçu en mars 1981.

Accepté en juillet 1981.

Acknowledgements. - This work was supported by NATO grant 1305, NSERC Canada, C.N.R.S. France Exchange Scientist grants to R. Billard and R. E. Peter, NSERC Canada grant A6371 to R. E. Peter, and INSERM grants to R. Billard. The drawings were made by J. Gallé.

Résumé. Le présent article décrit un appareil de stéréotaxie et une technique pour le positionnement d'électrodes dans les noyaux du diencéphale de la truite Arc-en-ciel pesant entre 120 et $140 \mathrm{~g}$, et sexuellement immature. Les noyaux du diencéphale sont identifiés sur un atlas établi à partir de coordonnées stéréotaxiques externes. 


\section{References}

BAUCHOT R., PLATEL R., RIDET J., THIREAU M., 1973. L'encéphale de Salmo gairdneri Richardson (truite arc-en-ciel) (Pisces, Teleostei, Salmonidae). Recherche d'une grandeur de référence pour des études quantitatives. Acta. zool., 54, 53-64.

BILLARD R., PETER R. E., 1977. Gonadotropin release after implantation of antiestrogens in the pituitary and hypothalamus of goldfish, Carassius auratus. Gen. comp. Endocr., 32, 213-220.

CRIM L. W., PETER R. E., BILLARD R., 1981. Onset of gonadotropic hormone accumulation in the immature trout pituitary gland in response to estrogen or aromatizable androgen steroid hormones. Gen. comp. Endocr., 44, 374-381.

DEMSKI L. S., 1978. Neuroanatomical substrates of reproductive behavior in male sunfish (Genus Lepomisl. Ann. Biol. anim. Bioch. Biophys., 18, 831-836.

DUBOIS M. P., BILLARD R., BRETON B., 1978. Use of immunofluorescence for localization of somatostatin-like antigen in the rainbow trout (Salmo gairdneri). Comparative distribution of LH-RF and neurophysin. Ann. Biol. anim. Bioch. Biophys., 18, 843-850.

DUBOIS M. P., BILLARD R., BRETON B., PETER R. E., 1979. Comparative distribution of somatostatin, $\mathrm{LH}-\mathrm{RH}$, neurophysin and $\alpha$-endorphin in the rainbow trout: an immunocytological study. Gen. comp. Endocr., 37, 220-232.

EKENGREN B., TERLOU M., 1978. Hypothalamic centers and innervation of the hypophysis in the Atlantic salmon (Salmo salar) and the rainbow trout (Salmo gairdneri). Ann. Biol. anim. Bioch. Biophys., 18, 837-842.

EPPLE A,, 1967. A staining sequence for $A, B$ and D cells of pancreatic islets. Stain Techn., 42 , 53-61.

MACEY M. J., PICKFORD G. E., PETER R. E., 1974. Forebrain localization of the spawning reflex response to exogenous neurohypophysial hormones in the killifish, Fundulus heteroclitus. $J$. exp. Zool., 190, 269-280.

PETER R. E., 1970. Hypothalamic control of thyroid gland activity and gonadal activity in the goldfish, Carassius auratus. Gen. comp. Endocr., 14, 334-356.

PETER R. E., 1977. Effects of midbrain tegmentum and diencephaion lesions on swimming and body orientation in goldfish. Exp. Neurol., 57, 922-927.

PETER R. E., GILL V. E., 1975. A stereotaxic atlas and technique for forebrain nuclei of the goldfish, Carassius auratus. J. comp. Neurol., 159, 69-102.

PETER R. E., MACEY M. J., GILL V. E., 1975. A stereotaxic atlas and technique for forebrain nuclei of the killifish, Fundulus heteroclitus. J. comp. Neurol., 159, 103-128.

PETER R. E., PAULENCU C. R., 1980. Involvement of the preoptic region in gonadotropin releaseinhibition in goldfish, Carassius auratus. Neuroendocrinology, 31, 133-141.

PLYTYCZ B., 1974. Ontogenesis of the hypothalamic neurosecretory system in the trout /Salmo trutta trutta L.). Bull. Acad. Pol. Sci., 22, 709-712.

RIDET J. M., DIAGNE M., BAUCHOT R., PLATEL R., 1974. Etude quantitative de la variabilité intraspécifique des principales subdivisions encéphaliques de la truite arc-en-ciel Salmo gairdneri Richardson (Pisces, teleostei, salmonidae). Bull. Museum nat. Hist. nat., 224, 674703. 


\section{PLATES 1-38}

Atlas of the diencephalon. The number at the top of each drawing gives the distance in $\mathrm{mm}$ posterior of the zero point (see fig. 3). The lines of the grid were drawn to scale $0.5 \mathrm{~mm}$ apart. The numbers on the vertical (left) side of each grid give the distances down from the horizontal zero point. The numbers on the bottom side each grid give the distances from the midline. 


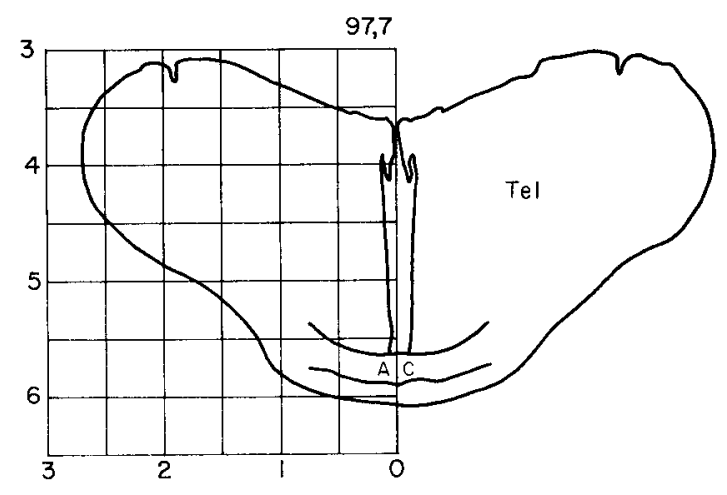

PLATE 1

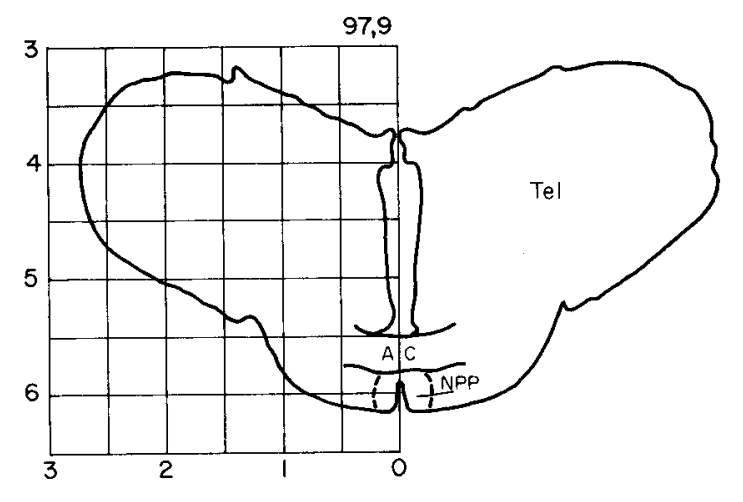

PLATE 2

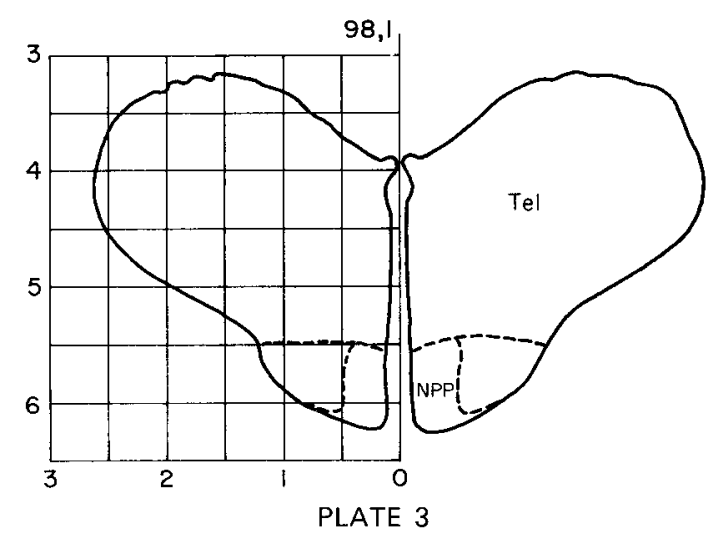



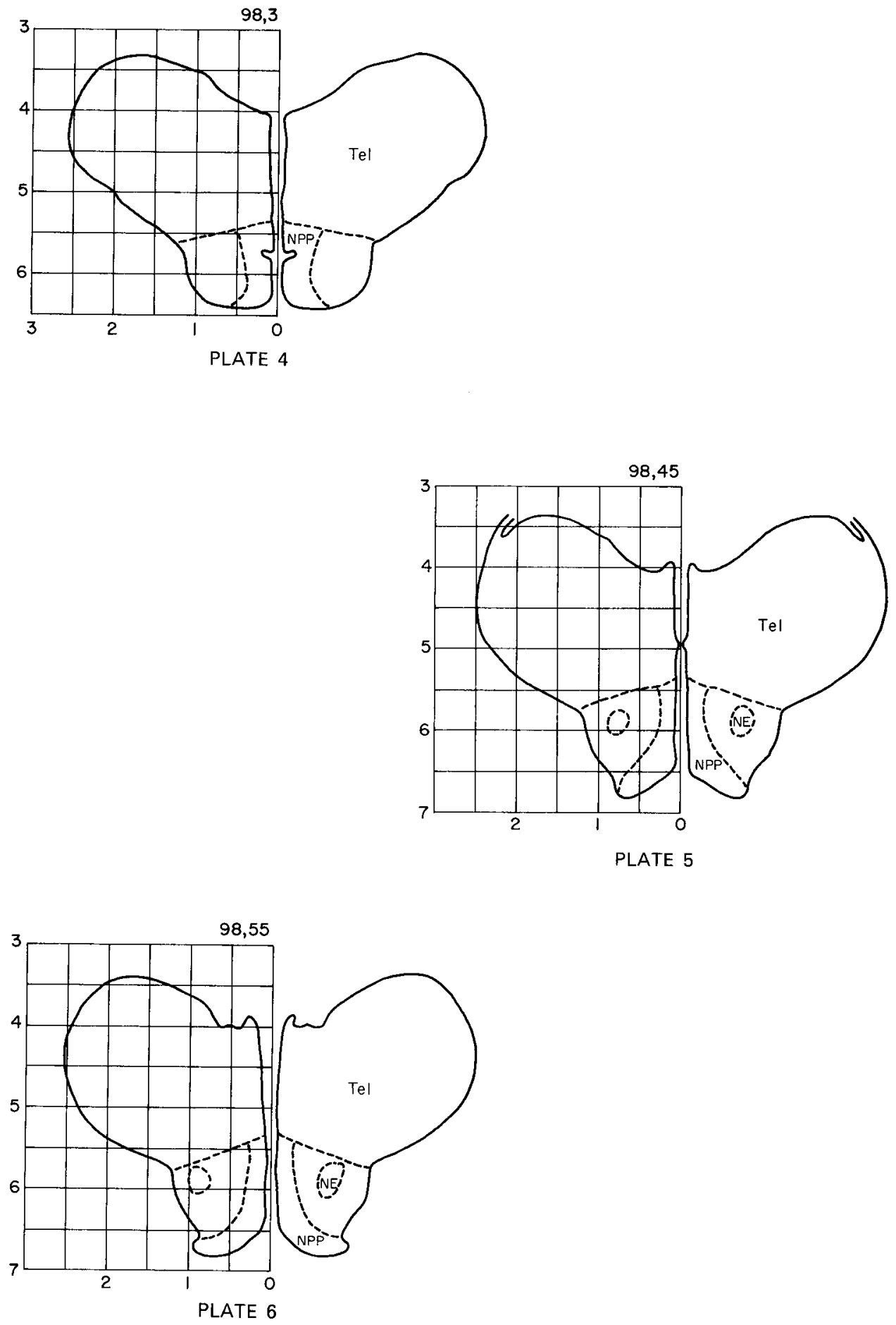

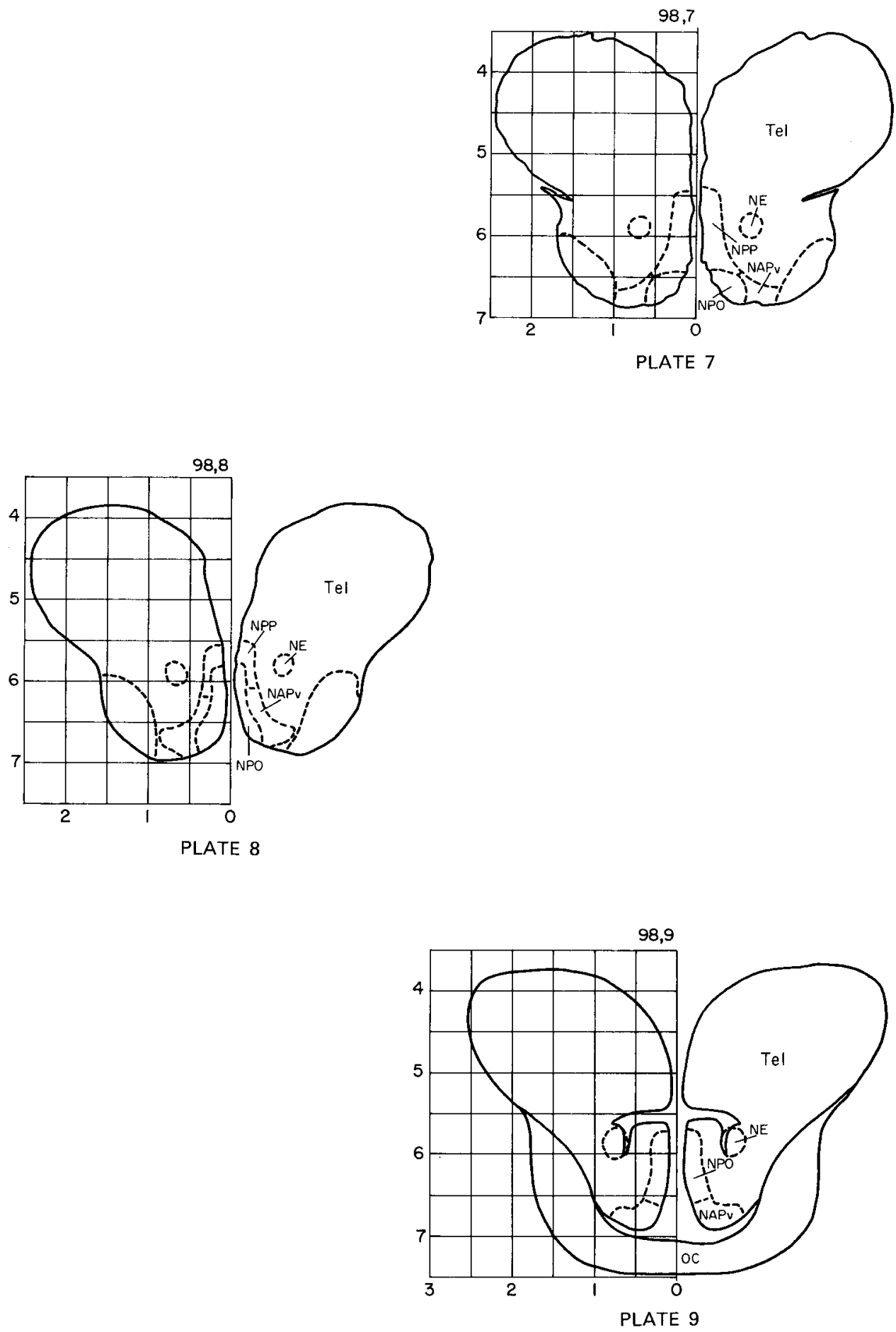

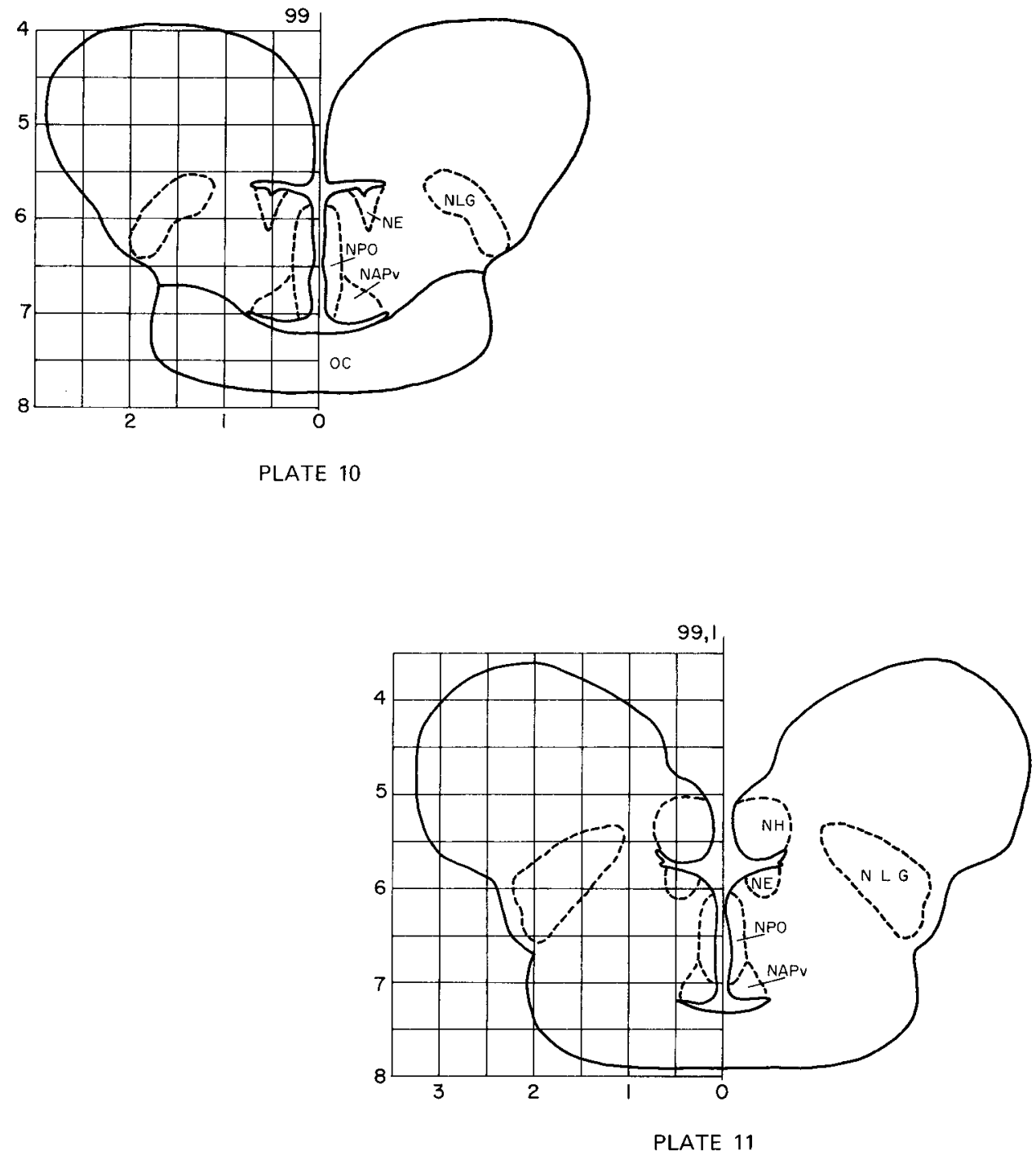
99,2

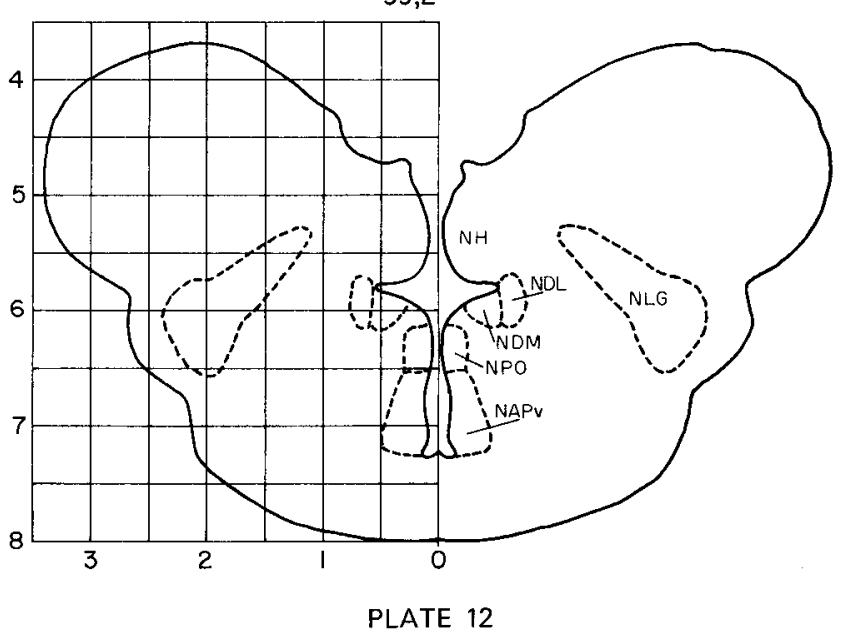

99,3

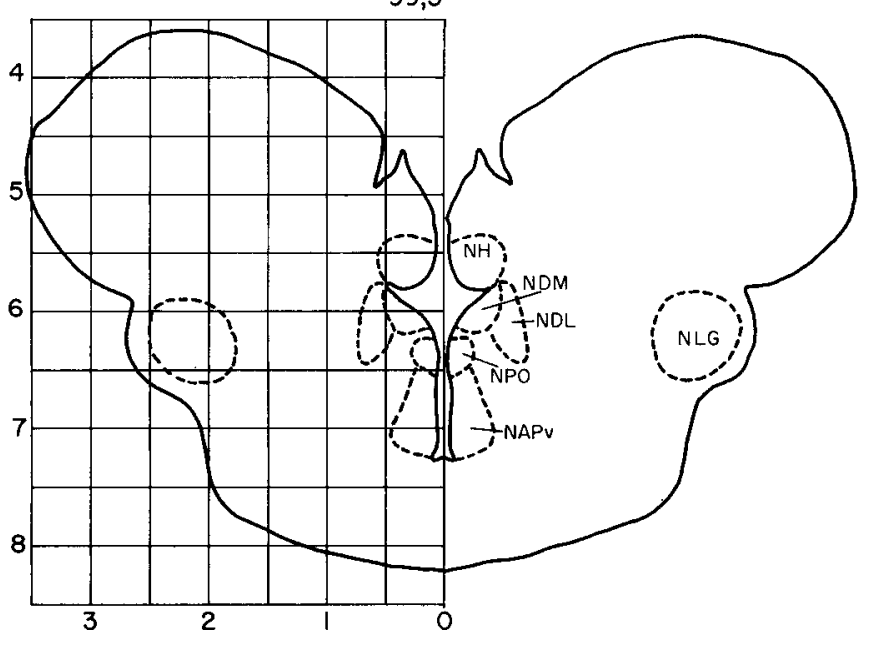

PLATE 13 

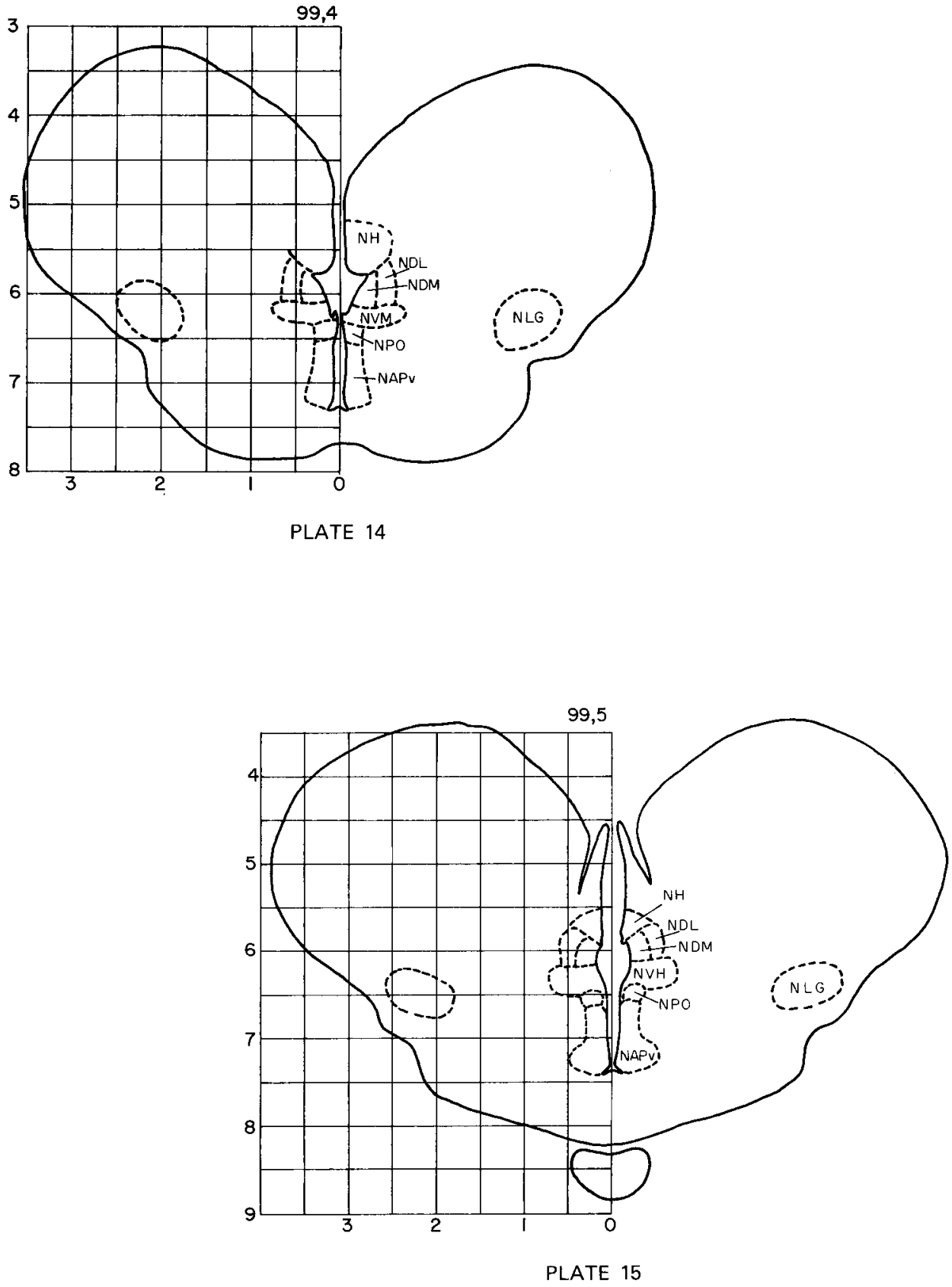

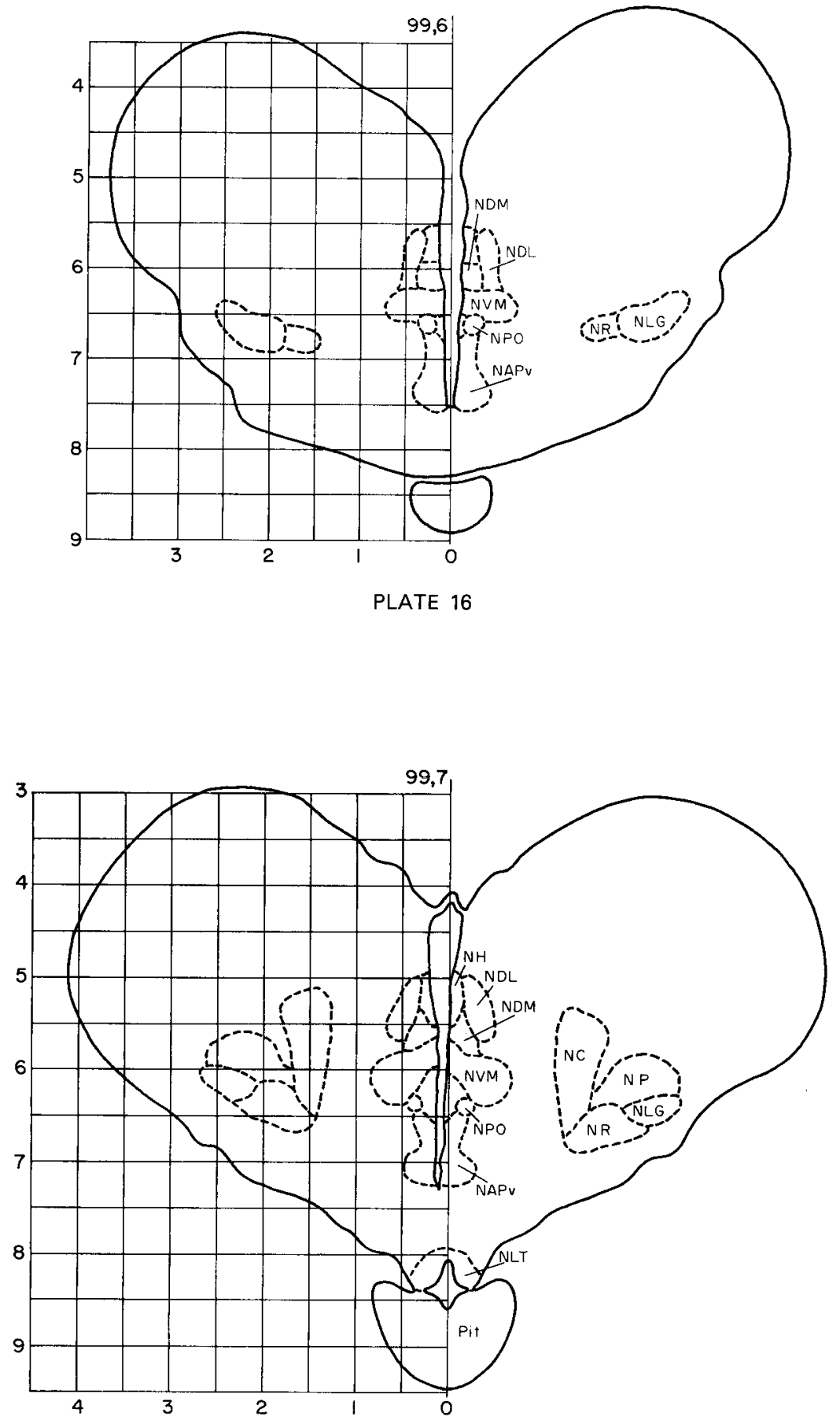

PLATE 17 

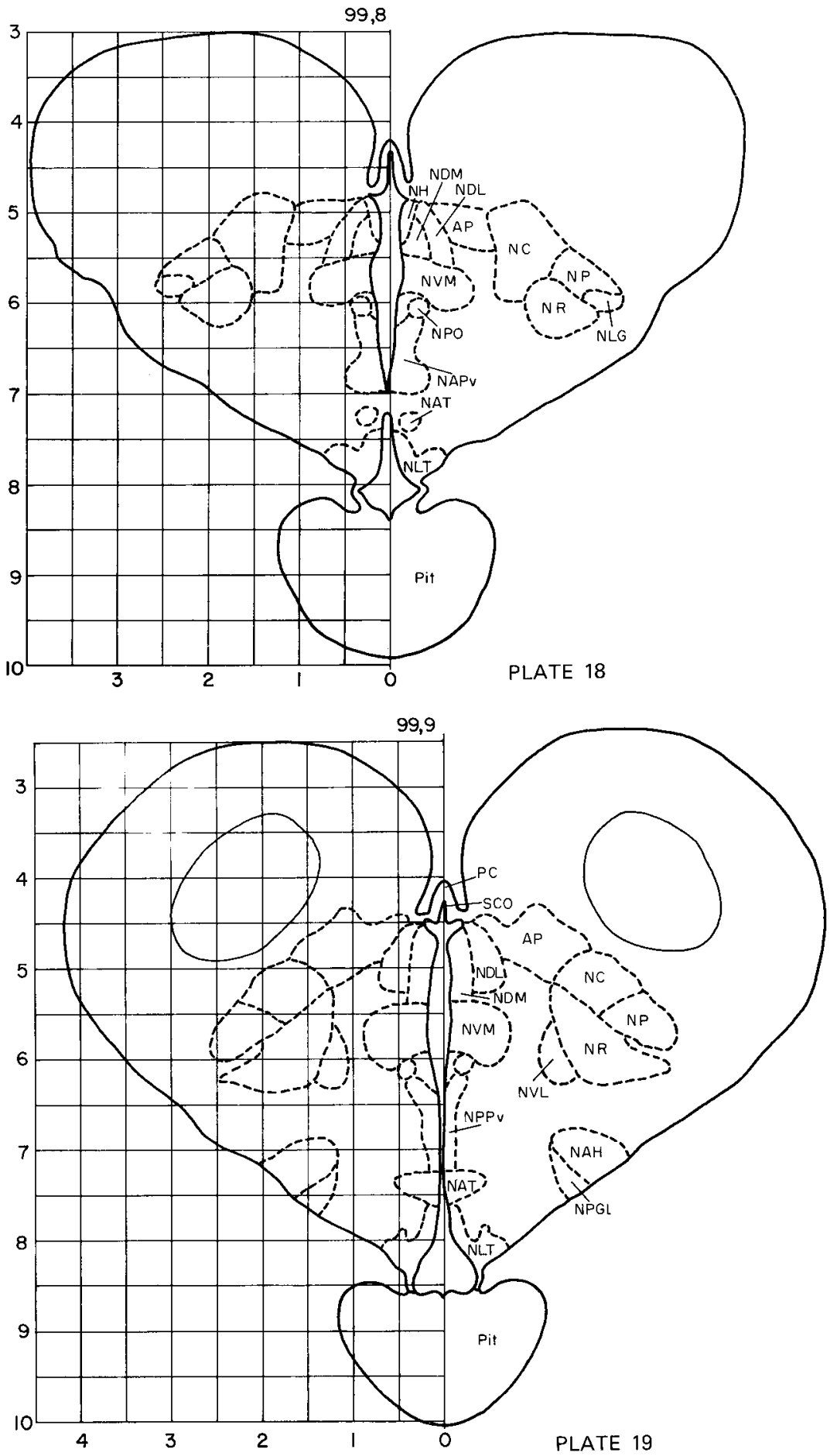

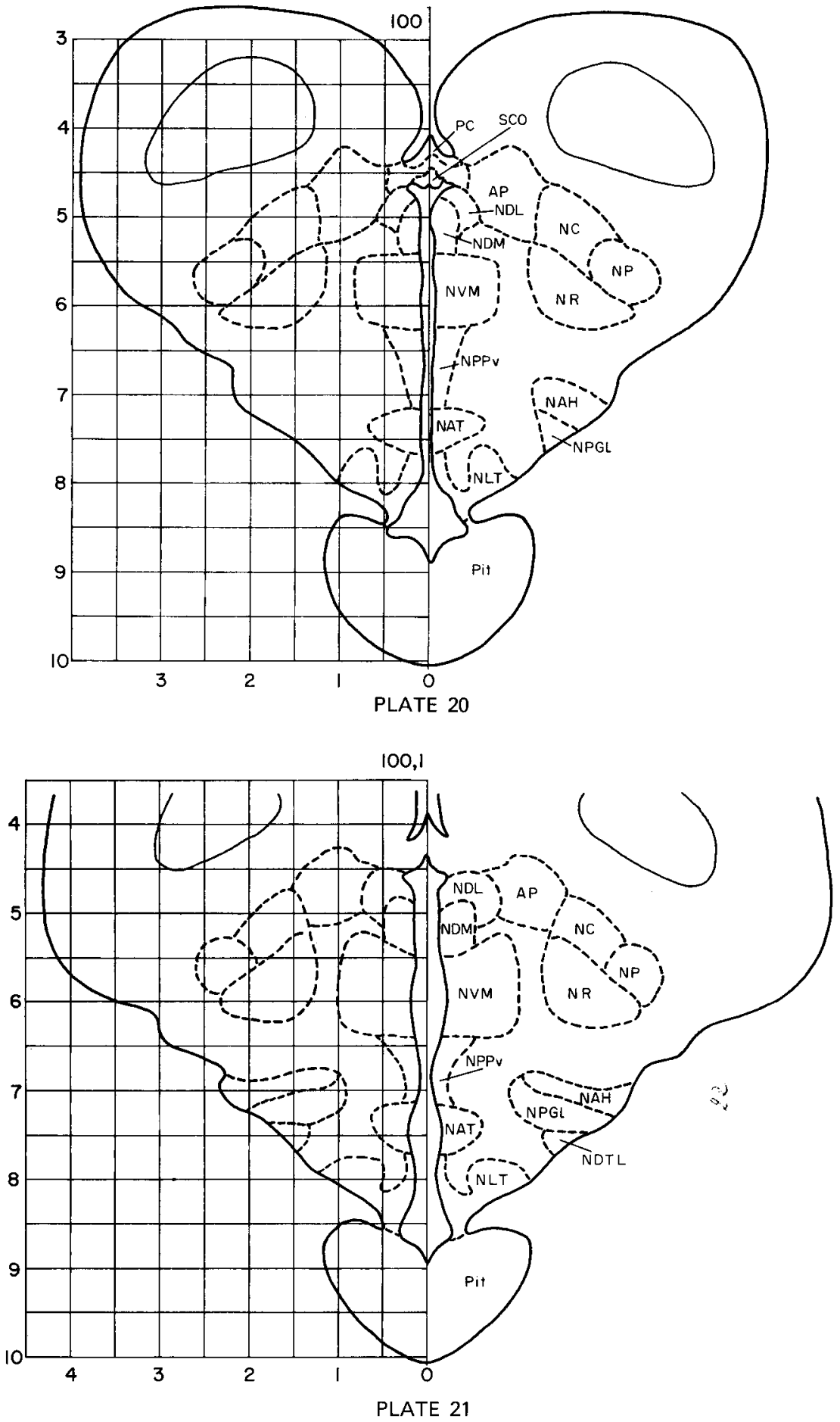

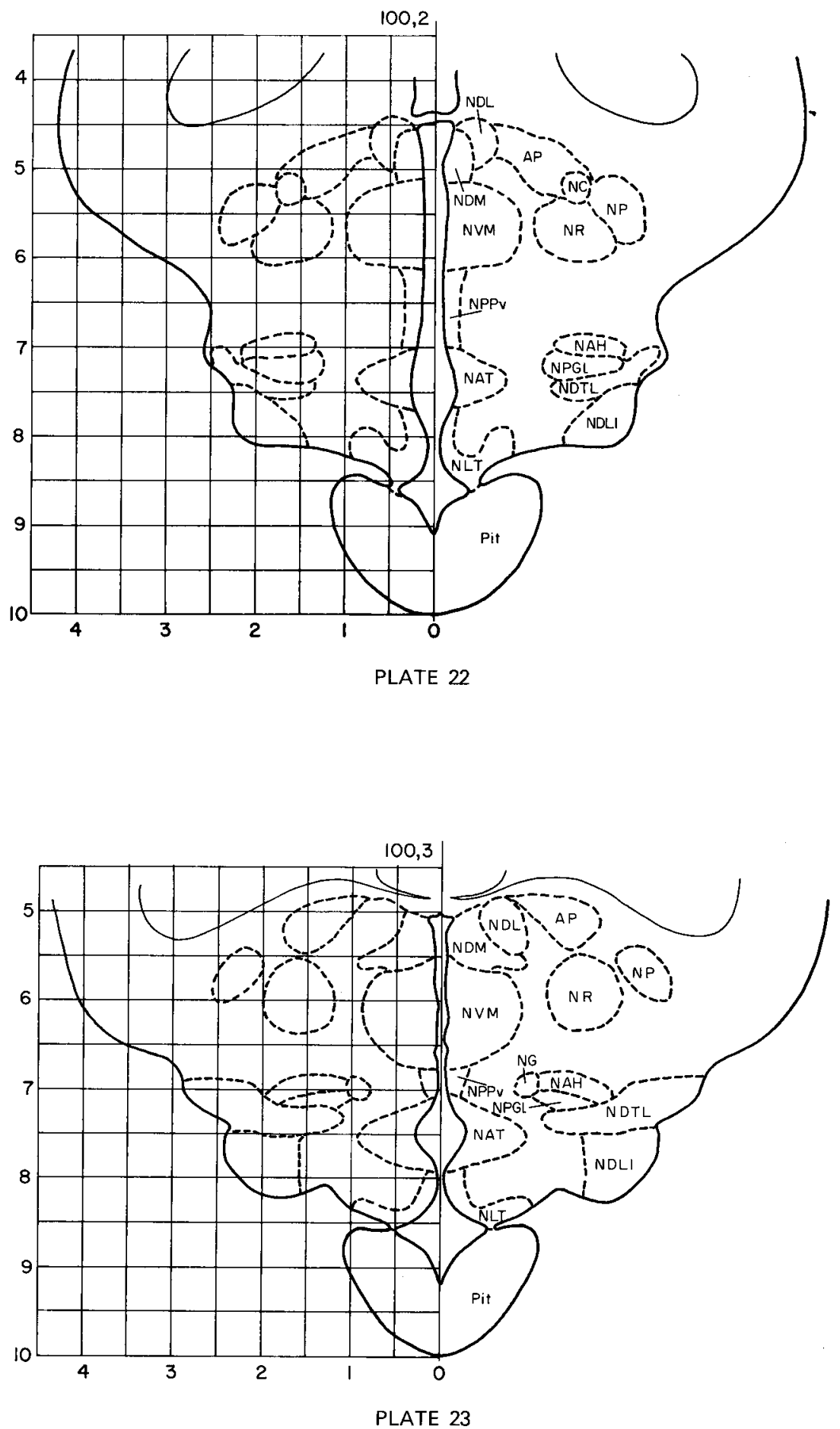

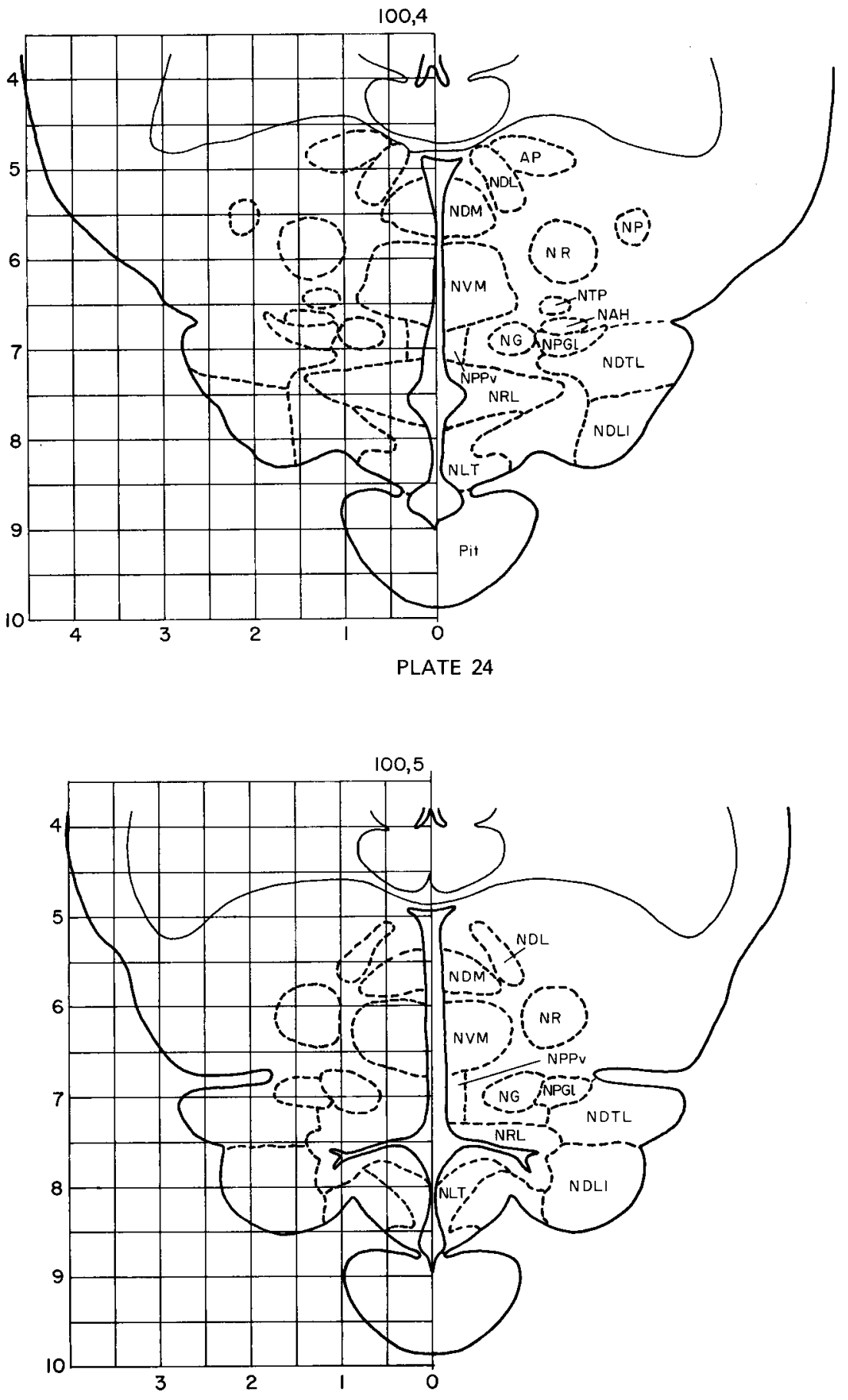

PLATE 25 


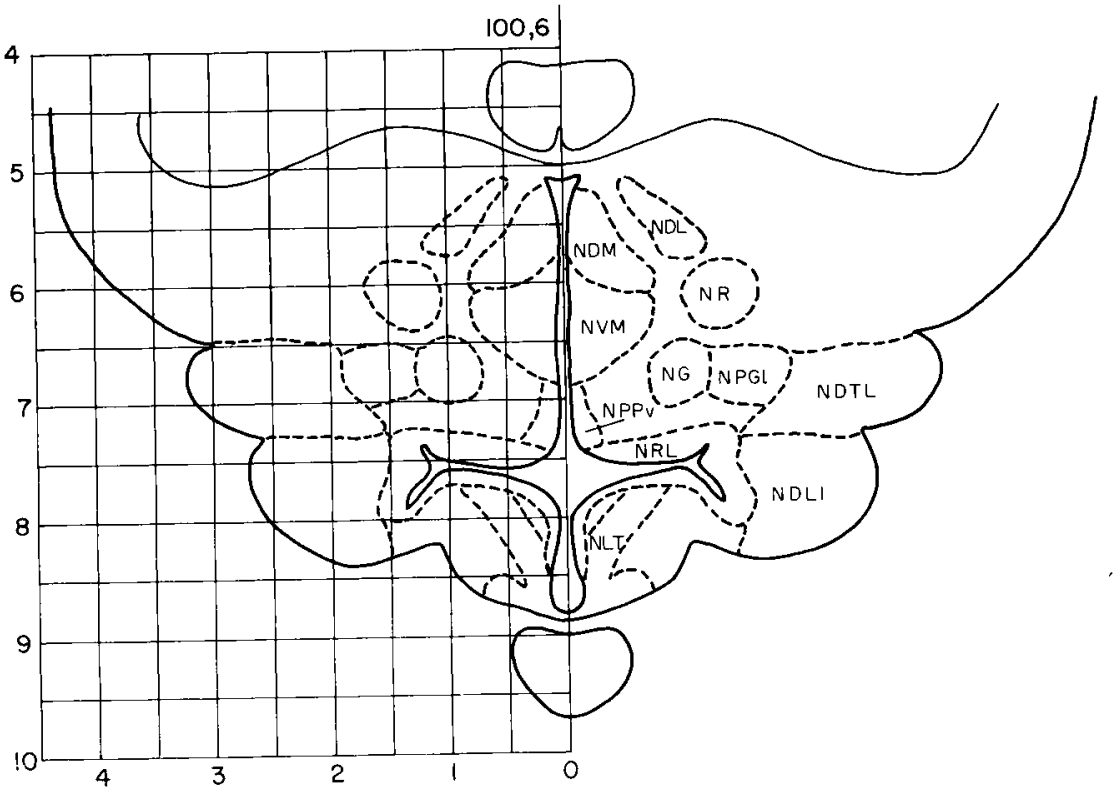

PLATE 26

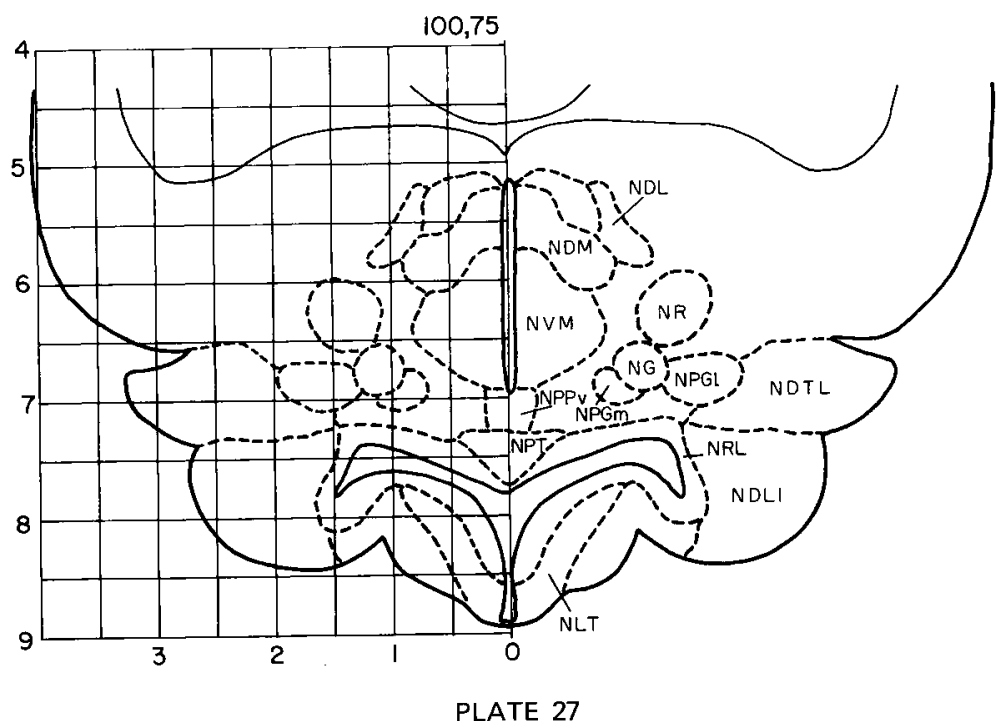




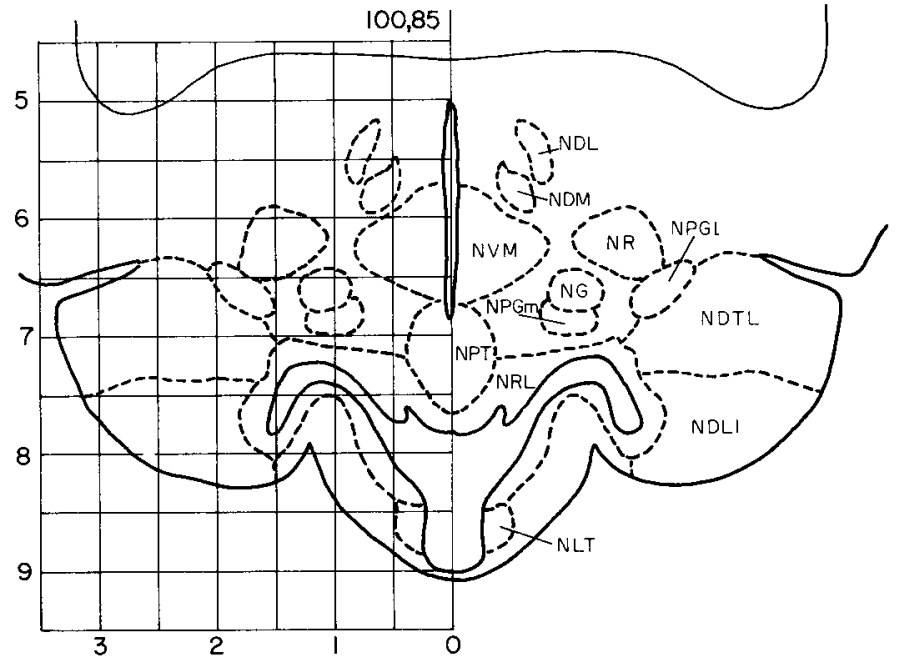

PLATE 28

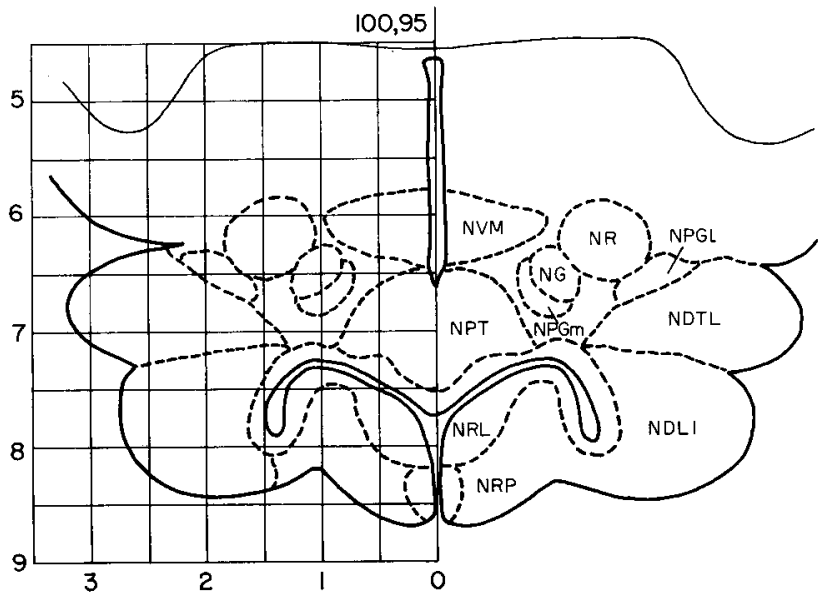

PLATE 29 


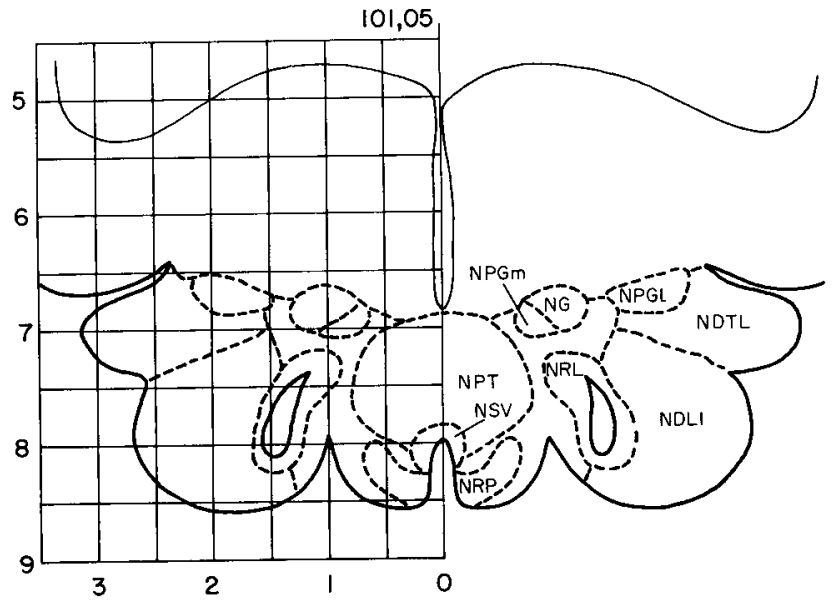

PLATE 30

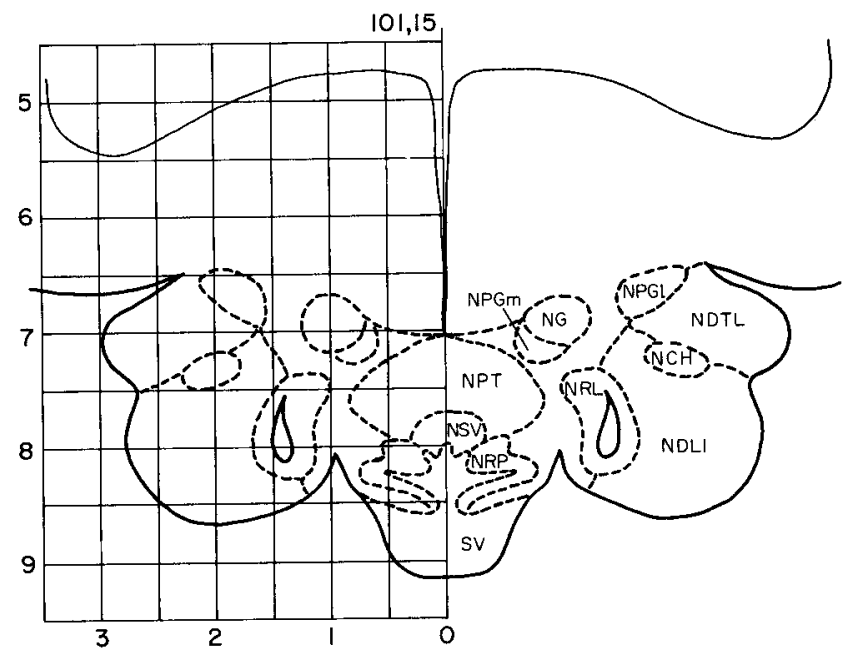

PLATE 31 


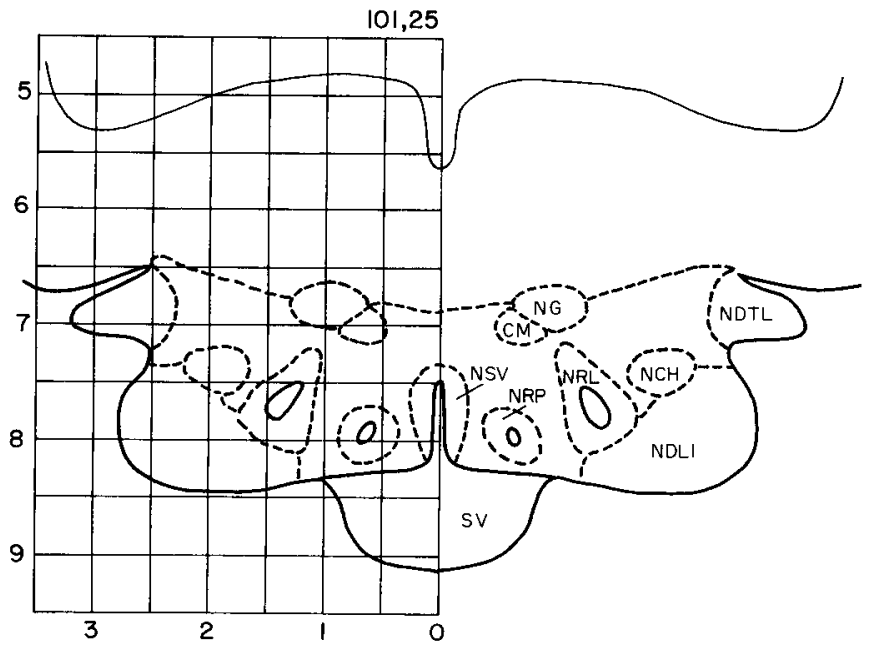

PLATE 32

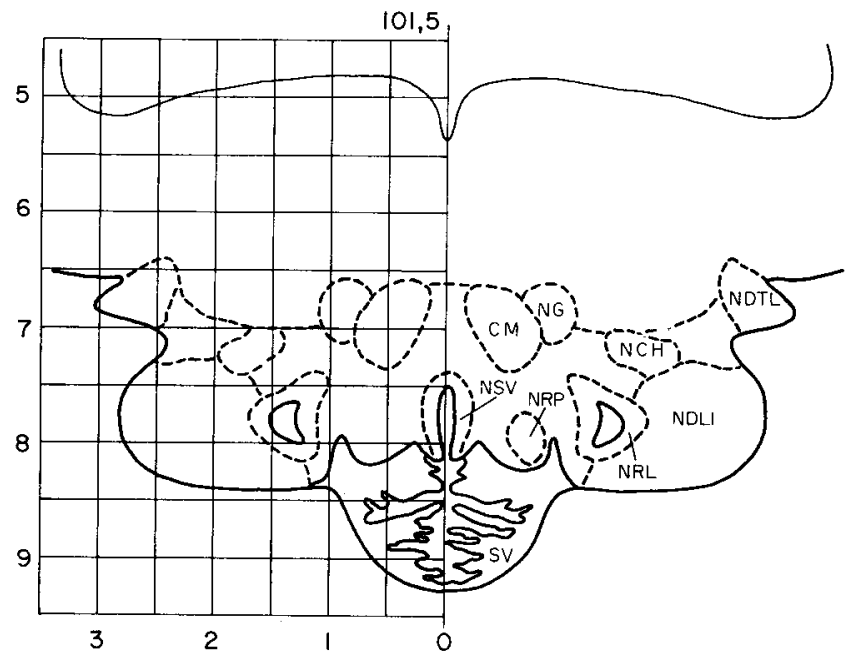

PLATE 33 
24

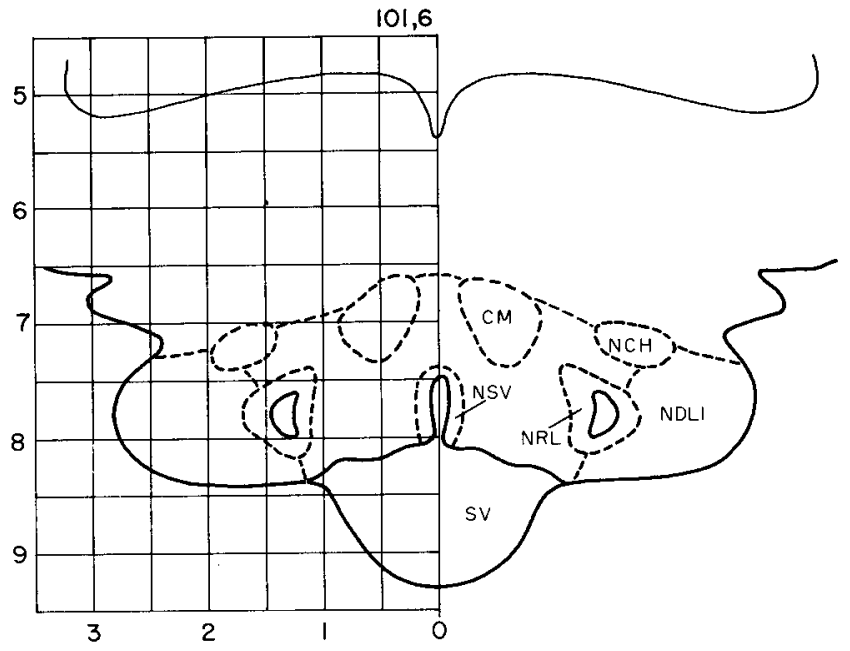

PLATE 34

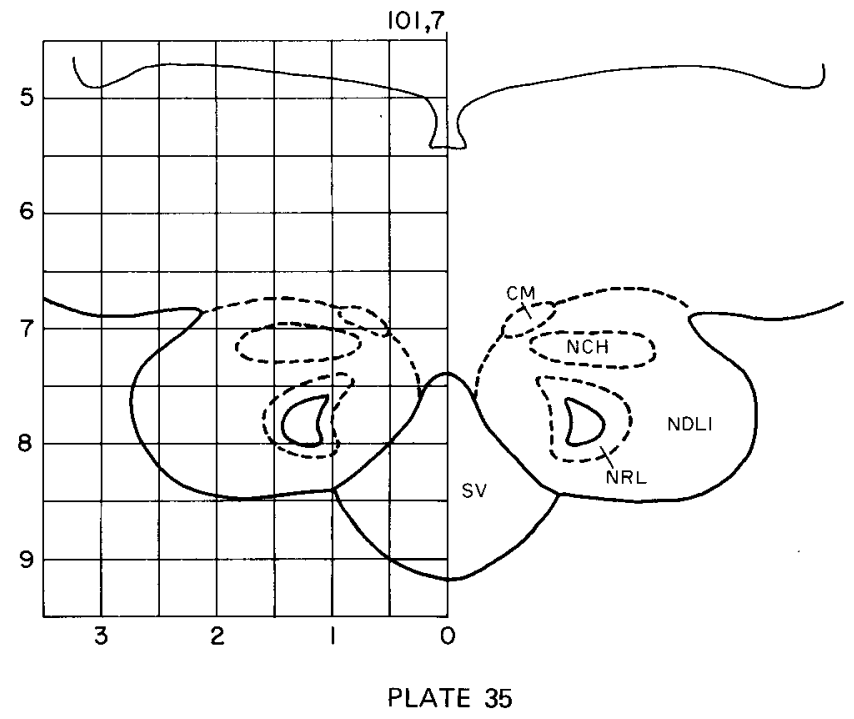


25
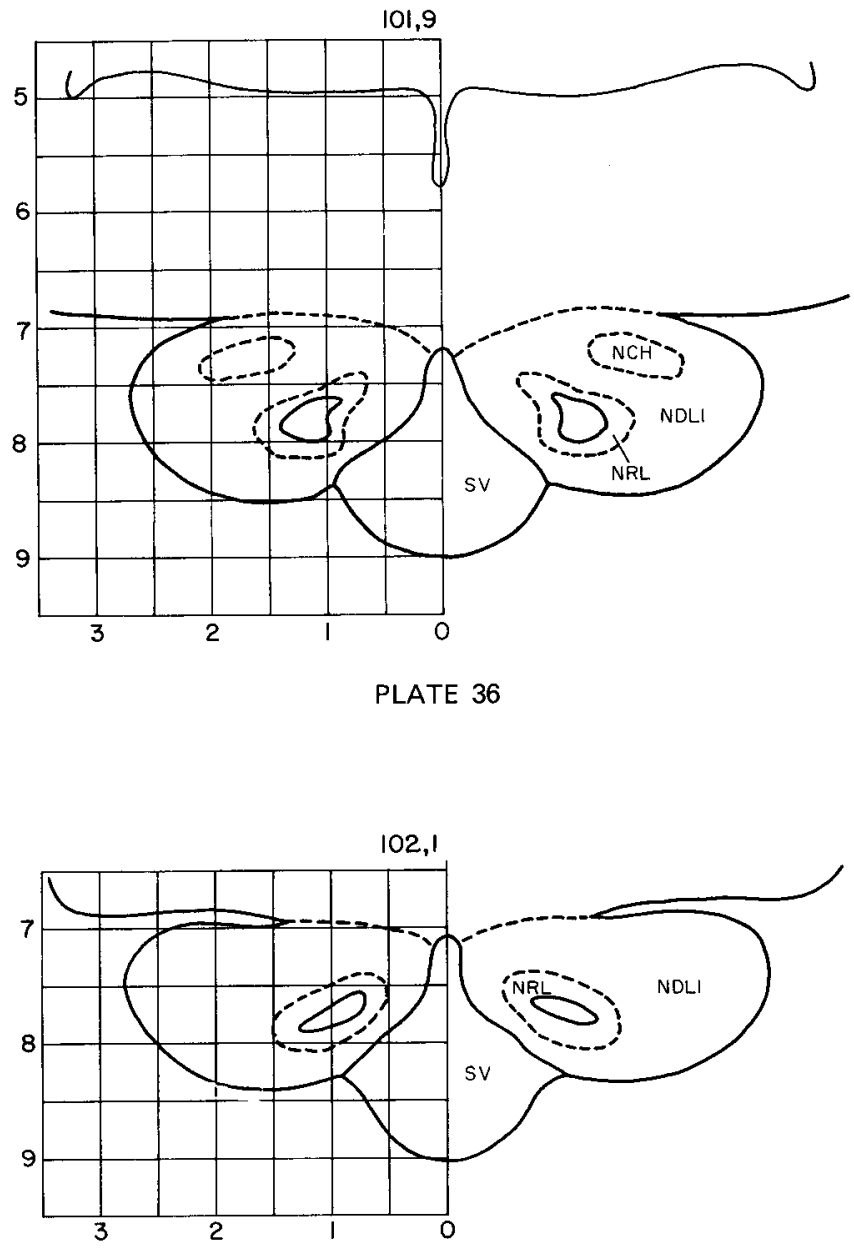

PLATE 37

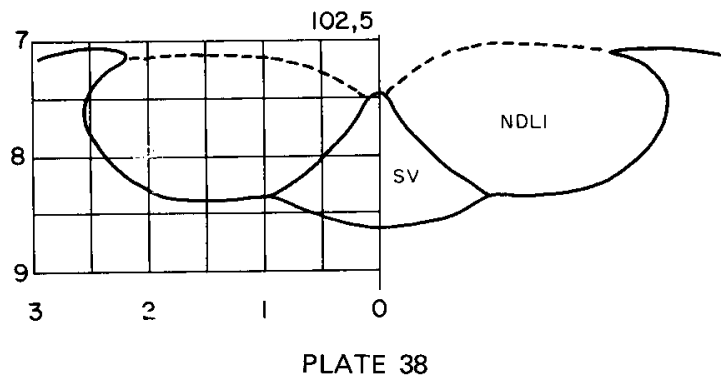

